\title{
Contribution of applying CDA in analysis of online news with different political views to translation of political texts
}

\author{
Mohamadreza Asemi Pour, Dr. Kollahi. S \\ Dept. of English Language Studies, Islamic Azad University Central Tehran Branch, Iran
}

Email address:

Kli_asemi@yahoo.com (M. A. Pour)

\section{To cite this article:}

Mohamadreza Asemi Pour, Dr. Kollahi. S. Contribution of Applying CDA in Analysis of Online News with Different Political Views to Translation of Political Texts. International Journal of Language and Linguistics, Vol. 1, No. 2, 2013, pp. 38-43. doi: $10.11648 /$ j.ijll.20130102.11

\begin{abstract}
This paper tries to investigate the impact of translators' knowledge of critical discourse analysis and transitivity on accuracy of translation, with comparison of online news sources, in both English and Persian. Critical discourse analysis takes language as a social practice with close relation to the social and historical context from which it emerges. Kress in Van Dijk (1985: 29) states, "Ideologies find their clearest articulation in language (Mahdiyan.M 2013), and Mahdiyan in his paper analyses the discursive construction of ideology in Bush's speech and flaws in its Persian translation due to translators' lack of dominance on CDA analysis. This article attempts to consider Cable News Network (CNN) and Fars News and Press TV online viewpoints on the danger of use of chemical weapons in 2013 domestic war in Syria, and tends to prove that without taking all sides of news website contradictory stands into consideration, Translation of political English news to Persian would not be flawless.
\end{abstract}

Keywords: CDA, Transitivity, Ideology, Translation

\section{Introduction}

When a translator attempts to perform an act of rendering within the framework of $\mathrm{CDA}$, the process should be target-oriented; that is considering translation as, Fact or product of the target culture' (Toury, 1995:29, Isbuga-Erel.R.F, 2007). Coming to Political context, the task ahead of translators is twofold; from one side, translator should have the required competence regarding the notions of knowledge and skills (Bell, 1991), but from the other side, he is expected to have acquired a sound knowledge of political discourse. O'Halloran insists on the notion of global groove and the fact that how a seemingly neutral text holds strong ideas for or against a piece of information, consequently, making it purposefully biased in favor of one side. Having that said, in translation, the recognition of all these subtle touches turns to be of utmost importance. As Bell puts it, any old fool can learn a language but it takes an intelligent person to become a translator'
Maydiyan in his paper has applied CDA analysis in translation of political speeches and interviews. It has been proved that works of translators in transferring one of Bush's speech about Iran's nuclear program to Persian have not been clear of mistakes due to absence of CDA analysis, also the fact that translation of political slanted text, holding ideology and being culture-bound, demands a profound insight about convincing strategies used to position reader in a particular ideological place.

Aside from analysis of source text (ST) in mentioned frameworks, and revealing the hidden ideology of political text, translator should be well aware of the cultural ground of target language. Moreover, As Fairclough puts it, a translator may choose to translate a particular text and intend the translation to function as an act of protest and resistance against the political establishment, but these subversive intentions may be relatively alien to the source-language text. Therefore, in order to meet the political interest of target culture when translator deals with two opposite sides, it is vital that aside from the source text that should be meticulously analyzed, translator should 
attain a sound knowledge of each topic in media of the target text (TT).

In this paper, with application of CDA, some online news about one topic both in English and Persian has been analyzed. The aim of research of Mahdyan (2013) was to investigate the way this analysis can help a translator to tackle ST from perspectives of the situational and social contexts, background information, linguistic choices, semantic and pragmatic relations. However, the main challenge here is whether from the examination of some texts in the target language about the same topic, translator can embark upon disclosing the effect of discursive, social and ideological constraints, norms and conventions which might lead to the true translation of ST. considering the rather small scope of this paper, analysis were mainly focused on the corpus, nevertheless any future work on the same topic might take into account the degree of translators cultural competence and the extent of effect of such feature on accuracy of translation. Besides, the influence of the translator experience in one specific field such as political text and discourse might be determined clearly. The findings may contribute to future work of translators by focusing their attention on significance of function of language in the socio-cultural context.

\section{Literature Review}

\subsection{Critical Discourse Analysis and Systemic Functional Linguistic}

During the past 2 decades there has been a shift in linguist approach to language studies, an inclination to discourse analysis. The main attempt is to move from sentence analysis to text and to examine meaning through context.

A plenty of analytical framework from discourse analysis are drawn on. In this respect, we can name the functional linguistic of halliday, The rhetorical structure theory of Man and Thompson, the genre analysis of swales, and more importantly, what is the main concern of this article, critical discourse analysis developed by Fairclough.

CDA deals with meaning and context and the relational and epistemological purposes. Among various use for CDA, we may point out the implication of this framework for Translation setting, in particular, political context.

As Louis Sullivan puts it, the underlying fact of halliday's functional grammar is the dictum that, form follows function. Language is used to obviate certain human needs; therefore, there are some metafunctions defined as ideational, interpersonal, and textual. Ideational that finds expression in transitivity system, and helps to make sense of the world. Interpersonal comes with relations and things in system of mood; and finally textual is the implementation of the other two.

Under light of these systems, any given text may be studied and decoded, especially political news and texts which naturally carry a sense of complexity, being wrapped in discursive structures of ideologies and beliefs.

\subsection{Dynamic Reader Positioning and Global Groove}

One of the most prominent functions of CDA is to show the way a text tends to position reader to perceive social and political reality in a particular way (Fairclough, 1992; Mills, 1995; O'Halloran.k, 2010). O'Halloran in a study on a short extract from a news story in The Sun newspaper, UK tabloid, investigates how positioning is built up as the reader proceeds. One system to measure global groove is Appraisal.

Appraisal is the evaluating framework, defined in chosen systems of AFFECT, JUDGMENT, and GRADUATION in O'Halloran's paper (see O'Halloran 2010 for more detailed information on Appraisal ); whereby, the pattern of accumulation of meaning and the way such meanings are uttered both directly and indirectly are evaluated.

However, there are some problems with appraisal such as subjectivity of analysis. To obviate partiality of this evaluation, every corpus can be investigated with Concordancer software. Concordancer reveals lexico-grammar patterns, patterns of interrelating lexis (vocabulary) and grammar. If evaluation of text by concordancer discloses the same global lexico-grammatical groove as our appraisal did, this would be compelling evidence that our evaluation distances from intrusion of subjectivity.

\subsection{CDA in Translation}

Isbuga-Erel.R.F (2007) in her article, explores the role of $\mathrm{CDA}$ in translation. From the pertinent data, she concludes that due to the dominance of social and political situation over both original and translated text, a target-oriented approach should be adopted. Therefore, CDA may make connection between TT and social structures, processes, ideologies, and power relations of its target culture.

Van Dijk (1995, 1998) essentially perceives discourse analysis as the analysis of ideology, and argues throughout his works that one of the crucial social practices influenced by ideologies is discourse, which, in turn, influences how we acquire, learn, take on, change and reproduce ideologies (Isbuga-Erel.R.F , 2007).

Through analysis of discursive aspects of ideology, the impact of society on formation of text and the influence of text on society and members will be evident. In translation, nevertheless, it is hard to claim this two-way relationship, for translated texts are usually less powerful than the originals in challenging or changing the prevailing ideologies; hence, most of the time, they reproduce or legitimate the ideologies in question. It is this peripheral status of translation which brings about some constraints on translators, thus leading them to manipulate the ST with the 
aim of conforming to existing ideologies in the target culture (Funda.R, 2007).

Accordingly, it seems inevitable that translator has some other tasks aside from literary translation ahead which demands a reasonable degree of expertise to conduct; among which we can name the knowledge of discourse. Here the attempt has been to shed some light on the process of political text analysis within CDA and SFL frameworks that might lead to development of a more practical system of translation in this particular context.

\section{Methodology}

\subsection{Corpus}

So as to collect samples appropriate for the current research, the researcher chose three pieces of news from three different sources of online news. Cases were chosen from online sources as dependence on online information is certainly growing, also technically, further investigation by other means of software evaluative systems like concordance would be more accessible. All the three sources were selected according to the Google most visited among the both American and Iranian political news websites. CNN to represent West ideology regarding the existing situation of middle east and in particular Syria domestic war and the threat of use of chemical weapons by Syrian army against,' opposition group", and Press TV opposing view which denotes Iran's stand covering the same news from a differing standpoint, and Fars News with parallel perspective with Press TV, that covers news in Iran's local language (Persian).

Case 1. CNN news Obama must act on Syria chemical weapons

(CNN) -- The Obama administration has confirmed what we have been hearing for months, that chemical weapons have been used in Syria by the regime of embattled President Bashar al-Assad.

The news, revealed in a White House letter to Congress, presents President Obama with a stark question. Will the United States become directly involved in the two-year-old Syrian civil war?

Last August, Obama issued a stern warning to Assad. If he used chemical weapons, Obama said, even if he moved them in preparation for use, he would cross a "red line" that would have "enormous consequences." Before that, Obama had already declared that the regime would be "held accountable" if it made the "tragic mistake of using those weapons," a warning he repeated last month during a trip to the Middle East.

Case 2. Press TV

Militants fighting against the Syrian government have used chemical weapons against the army in Daraya near the capital, Damascus, military sources say.

According to a commander of the Syrian Presidential
Guard, at least seven Syrian soldiers were killed on Saturday after they were attacked by a chemical weapon which produced a toxic yellow gas.

The soldiers were reportedly killed within an hour after inhaling the gas.

Foreign-backed militants have repeatedly threatened to use chemical weapons against the army and pro-government civilians in recent days.

They have also threatened to contaminate Syria's drinking water supply in a bid to kill all Alawite Shias and the supporters of President Bashar al-Assad.

The militants' use of chemical weapons come as the US and its allies have alleged that the Syrian government possesses the deadly weapons and is prepared to use them against militants.

Syria has been experiencing unrest since March 2011. Many people, including large numbers of army and security personnel, have been killed in the turmoil.

A recent UN report has revealed that militants from 29 countries have so far infiltrated into Syria to fight against the Damascus government, most of whom are extremist Salafists.

The Syrian government has repeatedly said that the chaos is being orchestrated from outside the country, and that a very large number of the militants operating in the country are foreign nationals.

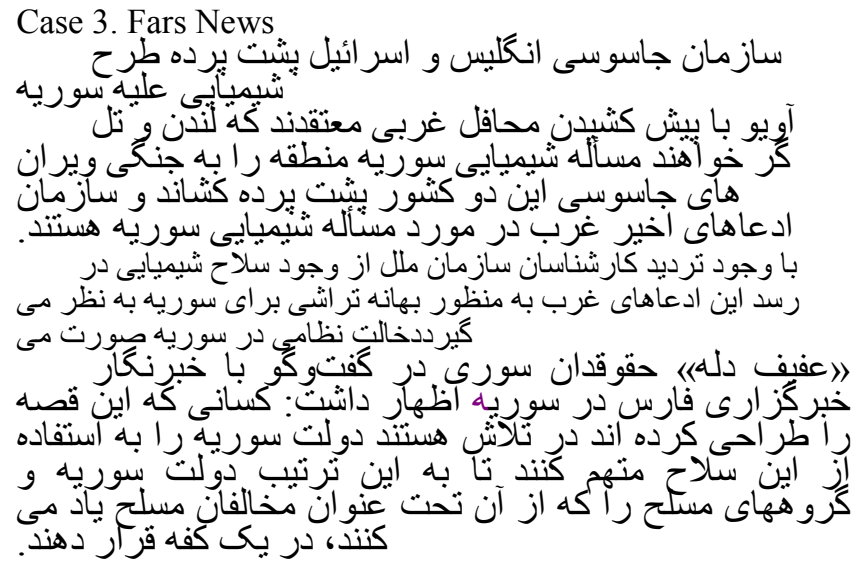

\subsection{Theoretical Framework}

With the intention of exploring the ideological position of readers, the unfolding of the argument, and finally tracing the build-up of evaluative meaning in the selected sections, APPRAISAL as an evaluative tool was chosen. APPRAISAL investigates text in propositional level and shows dynamic dimensions of evaluative meaning through resources such as; AFFECT, which includes a set of language resources for appraising experience in affectual terms; JUDGMENT, which appraise human behavior by reference to a set of norms; and GRADUATION, which contains a set of resources for grading. It is worth mentioning that There are more resources in appraisal system like; engagement, attitude, judgment, and 
appreciation which are not included in this research.

Since there have been criticisms about subjectivity of appraisal tool, researcher employed systemic functional grammar of Haliday as another control tool to evaluate the judgment of appraisal system and complement it, subsequently, obviate the probable error of subjectivity of appraisal system.

\subsection{Procedure}

In order to start the analysis each case was divided to sentences, and more particularly clauses which might be the unit of translation (Bell. 1991), that is more appropriate for such a study. Then all the chosen clauses and sentences are labeled according to appraisal tools which reveal the unseen intention of the writer with these choices of words. As maintained by Coffin.C and O'Halloran.k, the labeling can have an order as below:

Single underlining= judgment (less morally charged)

Double underlining= judgment (more morally charged)

Italics $=$ Indirect judgment

Bold $=$ Graduation

Dashed underlining $=$ AFFECT

$+\mathrm{ve}=$ positive

-ve= negative

Therefore each chosen case did undergo such an analysis and all the potential clauses and sentences were listed. Then the baldest words and phrases with possibility of carrying positive or negative load were spotted and identified in line with appraisal tools which as discussed earlier are judgment, affect, and graduation.

In Case one taken from $\mathrm{CNN}$, the procedure was carried on with these findings;

1. Chemical weapons have been used in Syria by the regime of embattled President Bashar al-Assad. (-ve judgment of Bashar al-Assad)

2. The news, revealed in a White House letter to Congress, presents President Obama with a stark question(+ve judgment of Obama)

3. Obama issued a stern warning to Assad(-ve judgment of Bashar al-Assad)

4. Obama said, even if he moved them in preparation for use, he would cross a "red line" that would have "enormous consequences(-ve judgment of Bashar al-Assad)

5. Obama had already declared (+ve judgment of Obama)

6. the regime would be "held accountable" if it made the "tragic mistake of using those weapons(-ve judgment of Bashar al-Assad)

7. a warning he repeated last month during a trip to the Middle East(-ve judgment of Bashar al-Assad)
Case two analysis (Press TV online) led to following findings:

1. Militants fighting against the Syrian government have used chemical weapons against the army(-ve of US and its allies)

2. at least seven Syrian soldiers were killed on Saturday after they were attacked by a chemical weapon(+ve of Syrian regime)

3. Foreign-backed militants have repeatedly threatened to use chemical weapons against the army and pro-government civilians(-ve of US and its allies)

4. They have also threatened to contaminate Syria's drinking water supply(-ve of US and its allies)

5. use of chemical weapons come as the US and its allies have alleged that the Syrian government possesses the deadly weapons(+ve of Syrian regime)

6. since March 2011 Many people, including large numbers of army and security personnel, have been killed(-ve of US and its allies)

7. A recent $U N$ report has revealed that militants from 29 countries have so far infiltrated into Syria to fight against the Damascus government(-ve of US and its allies)

8. The Syrian government has repeatedly said that the chaos is being orchestrated from outside the country(-ve of US and its allies)

9. A very large number of the militants operating in the country are foreign nationals.( -ve of US and its allies)

And finally investigation of Fars News declared :

منطقه را به جنكى وير انكر خو اهند كثاند (-ve of England and Israel)

اين ادعاهاى غرب به منظور بهانه نراشى براى دخالت نظامى (-ve of England and Israel)

(-ve of England and Israel)

تا به اين ترتيب دولت سوريه و كروههاى مسلح را كه از آن تحت عنوان

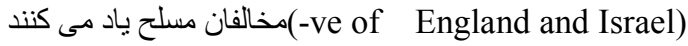

\section{Results and Discussion}

From the appraisal analysis, it is observable that a cumulative groove of evaluative semantic meaning is being shaped all the way down the text. The CDA analysis of three news sources revealed the positive or negative groove of each phrase as intended by the author; considering the likelihood of any partial side in the built-up to positioning of the reader, the number of positive represented by +ve and negative by $-\mathrm{ve}$, can now show the way how each text is set to channel readers idea into what is set to.

Table 1. displays the number of +ve, - ve and targets of judgment of the piece of news taken from $\mathrm{CNN}$; 
Table 1. targets of judgment (CNN)

\begin{tabular}{ccccc}
\hline & $\begin{array}{c}\text { Direct +ve } \\
\text { judgment }\end{array}$ & $\begin{array}{c}\text { Indirect } \\
+ \text { ve } \\
\text { judgment }\end{array}$ & $\begin{array}{c}\text { Direct }-\mathrm{ve} \\
\text { judgment }\end{array}$ & $\begin{array}{c}\text { Indirect-ve } \\
\text { judgement }\end{array}$ \\
\hline $\begin{array}{c}\text { Obama } \\
\text { Bashar } \\
\text { al-Assad }\end{array}$ & 0 & 2 & 0 & 0 \\
\hline
\end{tabular}

Table 2. shows the same type of information for the other two sources, Press TV and Fars News

Table 2. targets of judgment (Press TV and Fars News)

\begin{tabular}{ccccc}
\hline & $\begin{array}{c}\text { Direct +ve } \\
\text { judgment }\end{array}$ & $\begin{array}{c}\text { Indirect } \\
+\mathbf{v e} \\
\text { judgment }\end{array}$ & $\begin{array}{c}\text { Direct -ve } \\
\text { judgment }\end{array}$ & $\begin{array}{c}\text { Indirect -ve } \\
\text { judgement }\end{array}$ \\
\hline $\begin{array}{c}\text { US and } \\
\text { its allies } \\
\text { Syrian } \\
\text { regime }\end{array}$ & 0 & 0 & 2 & 5 \\
$\begin{array}{c}\text { England } \\
\text { and Israel }\end{array}$ & 0 & 2 & 0 & 0 \\
\hline
\end{tabular}

These findings can show how sentences and words that might be considered neutral or possibly ambiguous are now changed from a globally dynamic point of view.

For instance, in report of CNN of Syrian situation, in isolation, a warning he repeated last month during a trip to the Middle East is carrying no judgment whatsoever, but the co-text with negative judgment of Bashar al-Assad, positions readers to judge this as a negative interpretation which highlights the positive role of USA and Obama as the mediator whose main concern is the security and well-being of the Syrian people, and the threat Bashar al-Assad imposes to Syrian people and even the middle east.

On the other hand, PressTV portrays the situation with a phrase like: A recent UN report has revealed that militants from 29 countries have so far infiltrated into Syria to fight against the Damascus government, which with words like infiltrate, and other phrases and words like: orchestrated from outside and Foreign-backed militants, tries to place the reader indirectly in a position that the context wishes.

\section{Conclusion}

The content of the articles that form the three corpora of the present investigation might be said to tale a similar story of the latest Syria unrest, but a deeper analysis and interpretation showed that this was only applied at a superficial level. The CDA analysis showed only one way that the discursive structure of text might be revealed. However, with help of other frameworks like SFL and other tools like concordancer, further investigation of political context in order to highlight the groove and ideologies could be more enlightening.

Translation of such slanted text, which is the nature of political context, demands a thorough analysis of discursive structure, and a deep insight into the ideological intends of both ST and TT culture and context. This study attempted to show how a CDA analysis of a piece of news might be conducted not just for the ST, but also to show that so as to obtain a true understanding of the target culture and context, the target language sources should be analyzed as well.

Aside from the notion of spotting the ideological sides, Such analysis of target context may offer the most used and most suitable words and phrases about a chosen topic; consequently, guide the translator to more sensible and harmonious choices.

\section{Acknowledgment}

My special thanks go to Dr.Kollahi.S, whose enlightening advice helped me to pave the way and taught me research from A to $Z$. here I may appreciate the generous aid of Dr.Mottahari.M as well.

\section{References}

[1] Bell.R.T (1991). Translation and Translating: Theory and Practice (applied linguistics and language study), Longman group

[2] Coffin.C. ,O'Halloran.K. (2005). Finding the global groove: theorizing and analyzing dynamic reader positioning using appraisal, corpus, and a concordance, critical discourse studies 2 (2): 143-63.

[3] Fairclough. N. (1989). Language and Power. London: Longman.

[4] Fairclough. N. (1992a). Discourse and Social Change. Cambridge: polity press.

[5] Fairclough.N. and wodak.R. (1997). Critical Discourse Analysis, in van Dijk.T. (ed.) Discourse as social interaction, London: sage, pp. 268-84

[6] Haliday, M.A.K. (1973). Exploration in the Functions of Language. London: Edward Arnold.

[7] Halliday.M.A.K. (1994). An Introduction to Functional Grammar (2nd edition). London/ new York/ Sydney/ Auckland: Arnold

[8] Hernández.A.A. (2008). SFL and CDA: Contributions of the Analysis of the Transitivity System in the Study of the Discursive Construction of National Identity, The Linguistics Journal Volume 3, Issue 3 pp. 160-17

[9] House.j. (1986). A Model for Translation Quality Assessment. Tubingen: Narr.

[10] Isbuga-Erel.R.F (2007). A CDA approach to the translations of taboos in literary texts within the historical and socio-political Turkish context, University of East Anglia, Papers from the Lancaster University Postgraduate Conference in Linguistics \& Language Teaching, Vol. 2: Papers from LAEL PG 2007

[11] Kim.M (2007). translation error analysis: a Systemic 
Functional Grammar approach, in Kenny.D and Ryou.K (eds) Across Boundaries: International perspectives on translation studies, pp. 161-75, Newcastle upon tyne: Cambridge scholars publishing

[12] Knox, J.S. (2007). Visual-verbal communication on online newspaper homepage. Visual communication 6: 19-53

[13] Mahdyan.M, Rahbar.M, Maasoum.M.H (2013). applying critical discourse analysis in translation of Political Speeches and Interviews, Academic Journal of Interdisciplinary Studies Published by MCSER-CEMAS-Sapienza University of Rome Vol 2 No 1

[14] Matu.M.P., Lubbe.H.J (2007). Investigating Language and Ideology: A presentation of the ideological square and transitivity in the editorials of three Kenyan newspapers.
Journal of language and politics volume 6 number 3 p.401.

[15] Munday.J (2008). introducing translation studies: theory and applications (2nd edition), USA/Canada: Roultedge

[16] O'Halloran, K.L. (ed.) (2004). Multimodal Discourse Analysis: systemic functional perspectives. London: continuum

[17] Van Dijk. T. (1985). Prejudice in Discourse. Amsterdam: Benjamins.

[18] Van Dijk. T. (1993a). Discourse and Elite Racism. London: Sage.

[19] Van Dijk.A (1998). Handbook of Discourse Analysis http://www.hum.uva.nl/ teun/cda.htm 